\title{
When hunting benefits raptors: a case study of game species and vultures
}

\author{
Patricia Mateo-Tomás • Pedro P. Olea
}

Received: 3 June 2009 /Revised: 21 October 2009 /Accepted: 27 October 2009 / Published online: 18 November 2009

(C) Springer-Verlag 2009

\begin{abstract}
Management of hunting activity to serve as a tool for sustainable development has become a key issue in conservation biology. However, little evidence is available showing positive impacts of hunting on ecosystem conservation, limiting its capability to be used as a conservation tool. We analysed hunting and its positive influence on the ecology and conservation of the griffon vulture (Gyps fulvus), a scavenger with a relevant function in the ecosystem, in the Cantabrian Mountains, NW Spain. Use of the area by vultures was addressed by looking for cliffs used as roosts or colonies, and consumption of game species by vultures was evaluated through field surveys and questionnaires to hunters. Results revealed a strong spatiotemporal adjustment in the use of the area by vultures and hunting events, especially of red deer and wild boar. Vultures occupied roosting sites very close to the main hunting sectors of these game species and often were seen consuming their carcasses. The spatiotemporal pattern of roost use by vultures strongly overlapped with hunting of red deer. The numbers of both red deer and wild boar
\end{abstract}

Communicated by C. Gortázar

Electronic supplementary material The online version of this article (doi:10.1007/s10344-009-0341-9) contains supplementary material, which is available to authorized users.

P. Mateo-Tomás $(\square)$

Department of Biodiversity and Environmental Management, Faculty of Biological and Environmental Sciences,

University of León,

Campus de Vegazana,

24071 León, Spain

e-mail: pmatt@unileon.es

P. P. Olea

School of Biology, IE University,

Campus Santa Cruz la Real,

40003 Segovia, Spain hunting episodes within $3.5 \mathrm{~km}$ around the roosts were the best predictors of vulture occurrence and number. Our estimates show that hunting could feed around 1,800 vultures/ 6 months. Hunting can thus influence species at the top of the ecosystem (scavengers) and could aid sustainable management of griffon vulture populations, reconciling hunting and conservation. However, negative and positive impacts should be taken into account simultaneously for an overall evaluation of hunting on ecosystem conservation.

Keywords Ecosystem function - Griffon vulture · Hunting · Red deer $\cdot$ Roosts $\cdot$ Wild boar

\section{Introduction}

Hunting is one of the oldest forms of consumption of renewable natural resources by humans and has always been an integral part of rural cultures and traditions. Consumptive hunting has today been replaced by recreational hunting in many regions of the world, being currently a key issue for economic sustainability of many rural communities, especially in developing countries (Lindsey et al. 2007; Baldus et al. 2008). Hunting is also an important socio-economic activity involving millions of people, euros and hectares in most European regions (Lucio and Purroy 1992; Viñuela and Arroyo 2002). However, the huge increase in recreational hunting in the last decades has prompted the need to develop specific regulations regarding environmental conservation (Brainerd 2007).

Hunting has become an important issue in conservation biology, widely discussed at both international and national levels (Lindsey et al. 2007; Baldus et al. 2008). Particularly, management of hunting activity as a tool for sustainable 
development is currently under discussion (Brainerd 2007; Baldus et al. 2008). To effectively achieve this objective, it is necessary to understand the influence that hunting can have on species and ecosystem conservation (Lindsey et al. 2007).

Many studies on this subject have highlighted a negative influence of hunting activity on biodiversity. Effects on game species include overexploitation (Lindsey et al. 2007), threats to genetic integrity (Blanco-Aguiar et al. 2008 and references therein) and modification of their behaviour (Benhaiem et al. 2008). Effects on non-game species reported include illegal killing of predators (Thirgood et al. 2000; Valkama et al. 2005), reduction of their prey (Lozano et al. 2007), modification of the animal behaviour (Casas et al. 2009) and decreases in recruitment of trees dispersed by game species (Nunez-Iturri et al. 2008). In contrast, relatively few studies have examined positive effects of hunting on wildlife and/or ecosystem conservation (but see Thirgood et al. 2000; Baker 1997; Lindsey et al. 2006, 2007; White et al. 2008).

Old World vultures mainly feed on large animals, including wild ungulates (Murn and Anderson 2008). The relationship between vultures and wild ungulate hunting has previously only been referred to (e.g. García-Fernández et al. 2005; Cade 2007). To our knowledge, the influence that hunting could have in the ecology and conservation of this scavenger guild has not been assessed. This is especially important in the current context of the global vulture crisis, mainly because the causes of this are largely related to the huge dependence of vulture populations on farming activity (Murn and Anderson 2008). For example, mortality from the veterinary drug Diclofenac has caused the collapse of many vulture species in Asia (Pain et al. 2003; Green et al. 2006). The sanitary restrictions derived from bovine spongiform encephalopathy are causing some European vulture populations to decline (Tella 2001; Camiña and Montelío 2006). It has been also highlighted that antibiotics used to medicate livestock are affecting vultures at least at individual level in Spain (Lemus et al. 2008). Vultures have important ecosystem functions (e.g. by accelerating return of nutrients, limiting spread of diseases from decomposing carcasses and avoiding an increase in problematic species such as rats and feral dogs), which are difficult to replace (Sekercioglu et al. 2004). Therefore, food sources other than intensive farming could be an interesting tool for managing vulture populations. Moreover, hunting could integrate sustainable use of natural resources with species and ecosystem conservation through maintenance of the scavenger guild.

In this work, we analyse the relationship between hunting and griffon vulture (Gyps fulvus, L.) ecology in a mountain ecosystem of NW Spain where there is a high density and diversity of game ungulate species (Junta de
Castilla y León 2006). Additionally, this area provides an example of a semi-natural griffon vulture-dominated scavenger community, since here there are neither intensive farming systems nor feeding stations (i.e. places where food is provided to scavenging birds; Camiña and Montelío 2006). First, we studied spatiotemporal patterns of hunting and vulture activity looking at how one adjusts to the other. Second, we assessed consumption of game species by vultures and estimated potential availability of this resource through field surveys and questionnaires to hunters and local authorities. Third, we analysed the relative importance of game species, number of hunting episodes and amount of food available in the field to explain occurrence and number of vultures. We discuss the potential role that hunting could have in the management of vulture populations and therefore in an important part of ecosystem structure and function.

\section{Materials and methods}

\section{Study area}

The study area covers around $3,000 \mathrm{~km}^{2}$ in the Cantabrian Mountains (mainly northeast of the León province; also including Picos de Europa and neighbouring regions in Asturias, Cantabria and Palencia), NW of Spain (Fig. 1). It is located in a transition area between Temperate and Mediterranean climates, with most of the area having a Temperate climate characterised by high precipitation (mean annual rainfall $\mathrm{Pm}=1,608 \mathrm{~mm}$ ) and short, relatively cool summers (mean temperature $\mathrm{Tm}=17^{\circ} \mathrm{C}$ ). These characteristics make the landscape highly heterogeneous, with a wide variety of habitats ranging from oak and beech woodlands, pastures devoted to livestock rearing, to rocky outcrops (Junta de Castilla y León 2003). Extensive livestock rearing, mainly of cows, is one of the most important activities in the area. Livestock stay in the field 6-7 months per year between April and October, depending on the presence of snow. Transhumant livestock, mainly consisting of cows and sheep, are also present in this area during summer (Olea and MateoTomás 2009).

The study area is centred on the Riaño and Mampodre Regional Game Reserves (Fig. 1), which border to the north on the Aller, Caso and Ponga Regional Game Reserves and to the east with the Fuentes Carrionas and Saja Regional Game Reserves. All of these areas are regulated by public administrations, which auction every year a number of individuals of every species according to game standards and species censuses (Junta de Castilla y León 2006; local authorities, personal communication). Together, these reserves have every year more than 3,000 hunting episodes (Junta de Castilla y León 2006; Principado de Asturias 


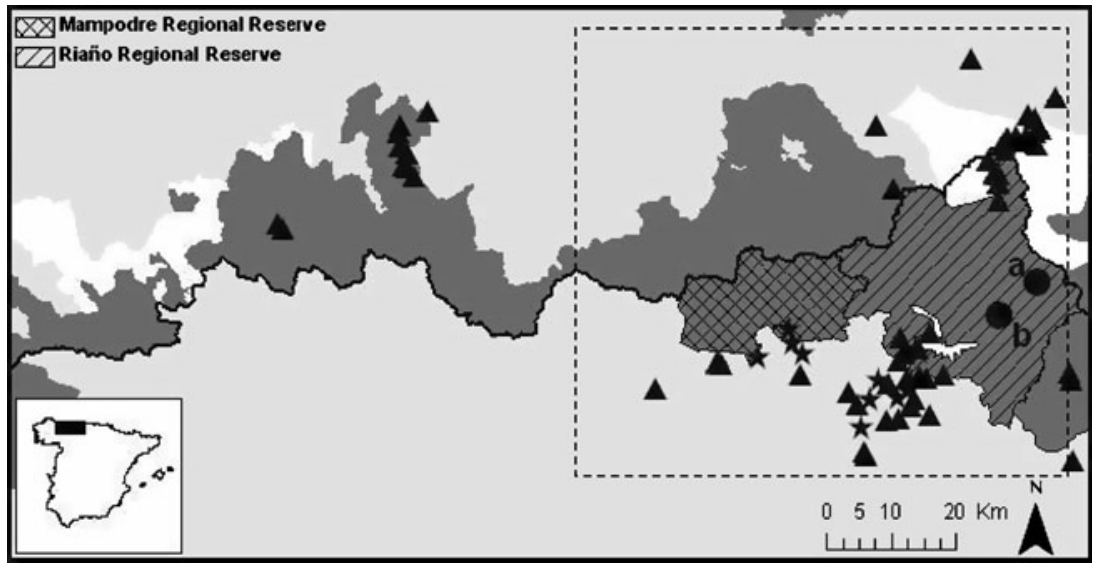

Fig. 1 Study area. Classification of the western region of the Cantabrian Mountains according to the type of hunting areas: private reserves in light grey, regional reserves in dark grey and areas without hunting in white. The black line represents the limit between north and south slopes. Dashed square shows the study area that was used for

2007; Cantabria authorities, personal communication), with more than 1,000 (34\%) in the Riaño and Mampodre Regional Game Reserves (Junta de Castilla y León 2006). Here, around $95 \%$ of the hunting episodes focus on large ungulate species such as Cantabrian chamois (Rupricapra pyrenaica, Bonaparte), red deer (Cervus elaphus, L.), European roe deer (Capreolus capreolus, L.), Iberian wild goat (Capra pyrenaica, Schinz) and wild boar (Sus scrofa, L.; local authorities, personal communication). A small proportion of the mountain range and most of the hunting areas in the low mountain range are private reserves (Fig. 1). These private reserves also have good conditions for large ungulate hunting but mainly focus on European roe deer and wild boar (hunted in $98 \%$ and $100 \%$ of the surveyed private reserves, respectively; $N=60$ ), with red deer $(30 \%)$ and Cantabrian chamois $(20 \%)$ hunted in fewer reserves. European roe deer and Cantabrian chamois are mainly hunted during spring and summer, red deer and wild boar are hunted during autumn and winter, and Iberian wild goats are hunted throughout the year (Table 1). Only the wild boar is hunted by large hunting drives with several hunters (maximum 25) and dogs (maximum 14). The other ungulate species are mainly hunted by one person or small evaluation of the relationship between hunting and vultures. Solid circles are vulture roosts $(a$ and $b$ ). Triangles and stars show all known colonies of griffon vulture. Stars show highly surveyed colonies (one visit/month), and triangles correspond to colonies surveyed between four and seven times per year

group (two or three persons) without dogs (local authorities, personal communication).

\section{Study species}

The griffon vulture is a cliff-nesting, large-sized raptor widely distributed from the Mediterranean countries to India, as well as areas in the north of Africa. Once threatened, now the species is classified as of least concern in both Europe and the world (BirdLife International 2007). With around 22,700 breeding pairs (Del Moral and Martí 2001), the Iberian Peninsula holds one of the largest populations of this species in the Western Palearctic (Del Moral and Martí 2001). The griffon vulture is widespread in Spain, where it is also classified as of least concern (Del Moral and Martí 2001). Where cliffs are available, the species occupies very different habitats, from plains to low and high mountains, with the nests ranging in altitude from sea level to the high mountains (above 1,700 m.a.s.l.; authors, unpublished data). Griffon vultures breed mainly in colonies which have from few to hundreds of pairs (Donázar 1993). The breeding season extends from December/January until July, and the brood consists only

Table 1 Hunting schedule in the game reserves of the study area according to every game species

\begin{tabular}{|c|c|c|c|c|c|c|c|c|c|c|c|c|}
\hline Game species (mean weight) & Jan & Feb & Mar & Apr & May & Jun & Jul & Aug & Sep & Oct & Nov & Dec \\
\hline Cantabrian chamois $(27 \mathrm{~kg}$ ) & & & & $3 \%(16)$ & $3 \%(16)$ & $3 \%(16)$ & $3 \%(16)$ & $3 \%(16)$ & $3 \%(16)$ & $3 \%(16)$ & & \\
\hline Rupicapra pyrenaica & & & & $3.2 \%$ & $13.1 \%$ & $14.8 \%$ & $13.1 \%$ & $4.9 \%$ & $1.6 \%$ & $36.7 \%$ & & \\
\hline European roe deer $(24 \mathrm{~kg})$ & & & & 0 & 0 & 0 & 0 & & & & & \\
\hline Capreolus capreolus & & & & $5.3 \%$ & $46.7 \%$ & $27.6 \%$ & $20.4 \%$ & & & & & \\
\hline Red deer $(120 \mathrm{~kg})$ & 0 & 0 & & & & & & & $95 \%(104)$ & $95 \%(104)$ & 0 & 0 \\
\hline Cervus elaphus & $0.4 \%$ & $0.4 \%$ & & & & & & & $63.4 \%$ & $23.7 \%$ & $11.2 \%$ & $0.9 \%$ \\
\hline Iberian wild goat $(60 \mathrm{~kg})$ & & & $95 \%(52)$ & $95 \%(52)$ & $95 \%(52)$ & $95 \%(52)$ & & & & $95 \%(52)$ & $95 \%(52)$ & $95 \%(52)$ \\
\hline Capra pyrenaica & & & $4.2 \%$ & $12.5 \%$ & $41.7 \%$ & $16.7 \%$ & & & & $12.5 \%$ & $8.3 \%$ & $4.2 \%$ \\
\hline Wild boar (70 kg) & $65 \%(10)$ & $65 \%(10)$ & & & & & & & & $65 \%(10)$ & $65 \%(10)$ & $65 \%(10)$ \\
\hline Sus scrofa & $15.9 \%$ & $2.4 \%$ & & & & & & & & $17.1 \%$ & $39.0 \%$ & $25.6 \%$ \\
\hline
\end{tabular}

Grey boxes correspond to the hunting period for every species. The mean percentage of hunted individuals abandoned in the field is provided at the top of each box together with the kilogrammes of food available for vultures per abandoned individual (in parenthesis). The percentage of hunting episodes involving each species per month is provided at the bottom of each box $(N=1,000)$ 
of one chick (Donázar 1993; authors, personal observation). Griffon vultures use breeding colonies all year around but also use temporal communal roosts where high food availability has been detected (Parker 1987; Xirouchakis 2007; Olea and Mateo-Tomás 2009).

In the study area, the griffon vulture population is of around 350 breeding pairs and 1,100 individuals, applying the index used by Del Moral and Martí (2001) (authors, unpublished data; Parque Nacional Picos de Europa, unpublished data).

Vulture surveys and hunting activity

We evaluated the relationship between vultures and hunting mainly by studying occurrence of griffon vultures and hunting episodes across the study area. We identified, mapped and implemented on geographic information system the hunting areas within the study area (i.e. private reserves and sectors of regional reserves; Figs. 1 and 2). Target species, dates and locations of every hunting episode, together with the percentage of every piece abandoned in the field (Table 1), were obtained from official data and interviews with local authorities and experienced hunters. This method has been highlighted as useful for obtaining valuable data on food availability to vultures (Murn and Anderson 2008). To assess the reliability of the interviews, we collected the same information by directly attending hunting episodes $(n=$ 12). No noticeable differences were found between these data directly collected by us and those obtained from the interviews.

We evaluated the use of hunting areas by vultures by looking for cliffs used as roosts or colonies in the study area (Fig. 1). To do this, we reviewed previous censuses (Olea et al. 1999; Del Moral and Martí 2001) and carried out intensive field surveys from 2005 to 2008 (Olea and MateoTomás 2009; authors, unpublished data). During 2006 and 2008, we intensively surveyed roost sites located in 2005 by visiting them weekly from September to January, when most hunting occurs, and monthly the rest of the year. We performed every visit at the roosts within the first hour after sunrise or the last hour before sunset on days with good visibility and inspected the cliffs with telescopes $\times 20-60$. In every visit, we recorded the number of vultures roosting at the cliff. The nine largest colonies $(44.5 \%$ of the total population) were also monitored with monthly visits using the same census protocol as for roosts (Fig. 1).

We estimated the minimum daily intake of an adult griffon vulture to be $0.543 \mathrm{~kg} /$ day (at $\mathrm{Tm}=17^{\circ} \mathrm{C}$; Donázar 1993).

In order to collect data on ungulate carcasses consumed by vultures, we looked at the vulture feeding events recorded in the area from 2005 to 2008 . We gathered more than 1,500 field observation hours (mean \pm SE, $420 \pm 98 \mathrm{~h} /$ year) within the hunting sectors of the study area $(4 \pm 1$ surveys/sector/year; range, 2-30). Every survey consisted of a 2-h walking route randomly distributed within the hunting sector. One person looked for vultures using binoculars and telescopes $\times 20-60$ and recorded the location, number and activity of vultures detected and, when vultures were feeding, the species consumed. The number of feeding-sightings recorded in every hunting sector was divided by the number of survey hours in that sector to allow comparisons. Additionally, in order to obtain data on vulture consumption of hunted wild ungulates, we interviewed all the local authorities of the study area $(N=10)$ and a representative number of hunters (32 individual hunters and two hunting societies; $45 \%$ of total hunters of the study area) of both private and regional game reserves.

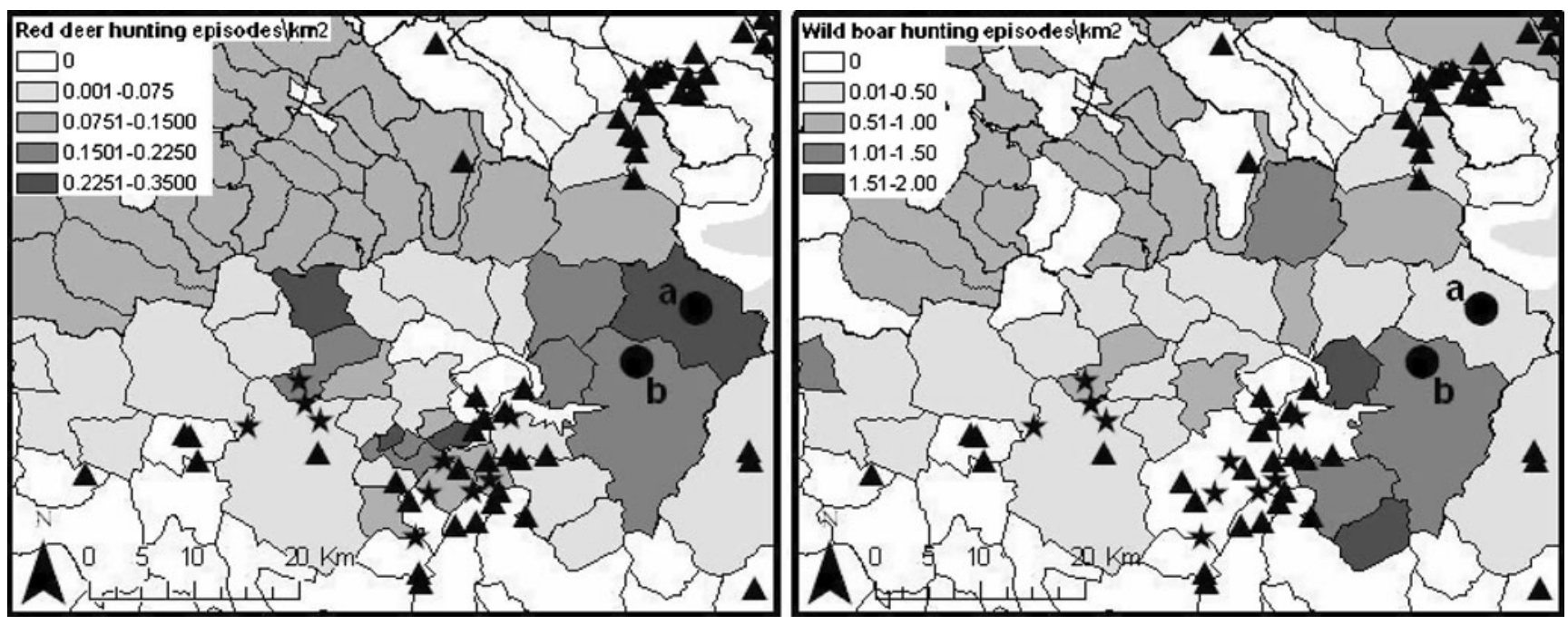

Fig. 2 Spatial distribution of the annual average number of hunting episodes focused on red deer (left) and wild boar (right) in the study area. Description of symbols like in Fig. 1 
Since interviews are not recommended for estimating frequencies of carcasses consumption by vultures (Murn and Anderson 2008), we used these data only to confirm the use of hunting remains by vultures.

\section{Data analysis}

Since we did not have precise information about foraging distances used by vultures, we considered various radii around each roost to estimate hunting episode frequency. We used the three following distances: half the distance to the nearest colony $(\mathrm{NNDc} / 2=7 \mathrm{~km})$, half the distance to the nearest roost $(\mathrm{NNDr} / 2=3.5 \mathrm{~km})$ and the sum of both $(\mathrm{NNDc} / 2+\mathrm{NNDr} / 2=10.5 \mathrm{~km})$, corresponding to the foraging area more intensively used around vulture colonies and roosts according to previous studies (Xirouchakis and Mylonas 2004; Olea and Mateo-Tomás 2009). To know which game species best explained the presence of vultures at the roosts over time, we used zero-inflated regression mixture models since our data set included many zero values. To control for this high number of zeros, these models have two components: (1) the count model, which controls the observed count state using a negative binomial regression with log link, and (2) the zero-inflated model, which controls the unobserved state (zero vs count) using a binomial model with logit link (Jackman 2008). The response variable was the monthly mean number of vultures at the roost; the median as the response variable was not informative here because their values were all zero. We calculated three different categories of variables for each game species at each considered radius (i.e. $3.5,7$ and $10.5 \mathrm{~km}$ ) around the roost: (1) number of hunting episodes (shots), (2) kilogrammes of food available for vultures $(\mathrm{Kg})$ and (3) hunting season (season), coded as $0-1$ according to species hunted during this month (1) or not (0). The modelling process was carried out separately for each category (i.e. shots, $\mathrm{Kg}$ and season), resulting thus in five explanatory variables (i.e. one for each game species) per category plus the categorical variable "roost". Firstly, we performed all possible model combinations $(n=64)$ for the count and the zero-inflated models independently. The resulting models were ranked using the corrected Akaike's information criterion (AICc; Burnham and Anderson 2002) and the Akaike weight of each model $\left(\omega_{\mathrm{m}}\right)$, estimated following Burnham and Anderson (2002). Within the count and the zero-inflated sets, we selected the best models as those included within $\Sigma \omega_{\mathrm{m}}=0.95$ (Burnham and Anderson 2002). A model filtering procedure was then applied by removing the more complex models that did not have a $\triangle$ AIC value lower than all the simpler models within which they were nested (Richards 2008). The best models of each set (i.e. count) were then combined with all the possible combinations of the other set (i.e. zero-inflated) to obtain the final best models through application of the same procedure described above. Finally, to obtain the relative contribution of each variable, we calculated their Akaike weights. The Akaike weight for each variable $\left(\omega_{\mathrm{i}}\right)$ was calculated by summing, from the set of models within the $95 \%$ probability, the weights of those containing the variable, such that the variables with the highest weight $\left(\Sigma \omega_{\mathrm{m}}\right)$ were the most important relative to the others. The analyses were performed in the R statistical software, using the pscl package in $\mathrm{R}$ Version 2.7.2 (R Development Core Team 2008).

\section{Results}

We found 50 breeding colonies and two roosts in the study area (a and b; Fig. 1). Both roosts have been used by vultures at least during the last 4 years (2005-2008). They were located on non-limestone cliffs narrower than those of the colonies, had a southwestern exposure (opposite that of most colonies, which face east) and were placed closer to roads (Table 2). Both roosts were located at the eastern edge of the griffon vulture main breeding area, 13.8 and

Table 2 Characteristics of the roosts and the colonies (mean \pm SE) of the study area

\begin{tabular}{lllll}
\hline Characteristics & Roost A & Roost B & Roost mean $(n=2)$ & Colony mean $(n=50)$ \\
\hline Elevation (m.a.s.1.) & $1,604.0$ & $1,289.0$ & $1,446.5 \pm 157.5$ & $1,321.7 \pm 39.1$ \\
Height (m) & 80 & 66 & $73.0 \pm 7.0$ & $93.1 \pm 9.5$ \\
Length (m)* & 261.3 & 180.6 & $220.9 \pm 40.3$ & $968.0 \pm 127.4$ \\
Exposure & SW & SW & SW & E \\
Substrate & Non-limestone & Non-limestone & Non-limestone & Limestone \\
Distance nearest colony (m)** & $13,840.0$ & $11,147.0$ & $12,493.5 \pm 1,346.5$ & $2,909.0 \pm 324.4$ \\
Distance nearest town (m) & $1,482.7$ & $1,948.6$ & $1,715.6 \pm 232.9$ & $1,705.2 \pm 119.8$ \\
Distance nearest road (m)** & 338.5 & 199.0 & $268.7 \pm 69.7$ & $1,240.3 \pm 128.5$ \\
\hline
\end{tabular}

Stars indicate significant differences between roosts and colonies, according to Wilcoxon rank tests

$* P<0.10$

$* * P<0.05$ 


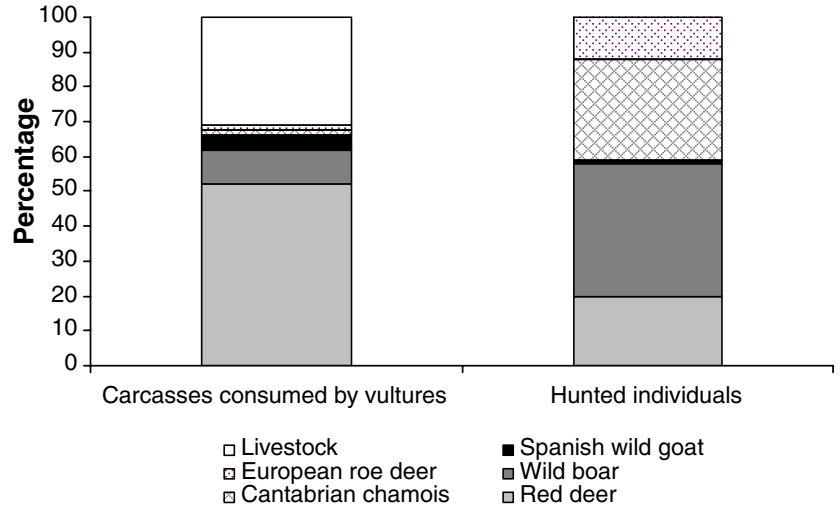

Fig. 3 Percentage of field observations of vultures feeding on game species $(N=49)$ and livestock $(N=22)$. Livestock included sheep and goats $(45 \%)$, cows $(27 \%)$, horses $(18 \%)$ and pigs $(9 \%)$. Percentage of individuals of each game species hunted each year in the study area $(N=1,000)$ is also shown

$11.1 \mathrm{~km}$ away from the nearest colony, respectively, and $7 \mathrm{~km}$ from each other (Fig. 1 and Table 2).

The two roosts were located in the hunting sectors with the highest number of shot wild ungulates, especially of red deer and wild boar (Fig. 2). The two roosts had far more shot wild ungulates around them $(3.5 \mathrm{~km})$ than the colonies did (red deer: mean \pm SE, $59.9 \pm 1.4$ vs $6.3 \pm 1.7$; Wilcoxon test, $Z=-2.32, P=0.02$; wild boar: $76.6 \pm 8.9$ vs $31.7 \pm 4.3$, $Z=-1.89, P=0.06$ and wild goat: $0.9 \pm 0.4$ vs $0.4 \pm 0.1, Z=$ $-1.76, P=0.08$; European roe deer $(14.9 \pm 3.4$ vs $12.0 \pm 0.9)$ and Cantabrian chamois $(26.9 \pm 4.6$ vs $17.9 \pm 3.7)$ showed non-significant differences, $P>0.10$ ).

Interviewed hunters gave evidence of griffon vultures feeding on hunting remains of red deer $(90 \%$ of interviewed hunters) and wild boar (60\%). Additionally, from our field surveys, 49 of $71(69 \%)$ sightings of vultures feeding on large-sized carcasses were on wild ungulate carcasses, mainly of red deer (76\%; Fig. 3). Spatial distribution of these sightings occurred around the main breeding area and, especially, around the roosts, in hunting sectors with a high number of shot wild ungulates (Fig. 2 and ESM 2).

During the 2-year intensive study, we observed roughly the same spatiotemporal pattern in the use of roosts (Fig. 4). Vultures appeared at roosts at the beginning of the red deer hunting season (September) and abandoned them in October, coinciding with the end of the red deer trophy hunting season. The relationship between presence of vultures and red deer hunting is clearly observed for roost
Fig. 4 Number of vultures (mean $\pm \mathrm{SE}$ ) at roosts and number of hunting episodes of each game species within $3.5 \mathrm{~km}$ radius around every roost
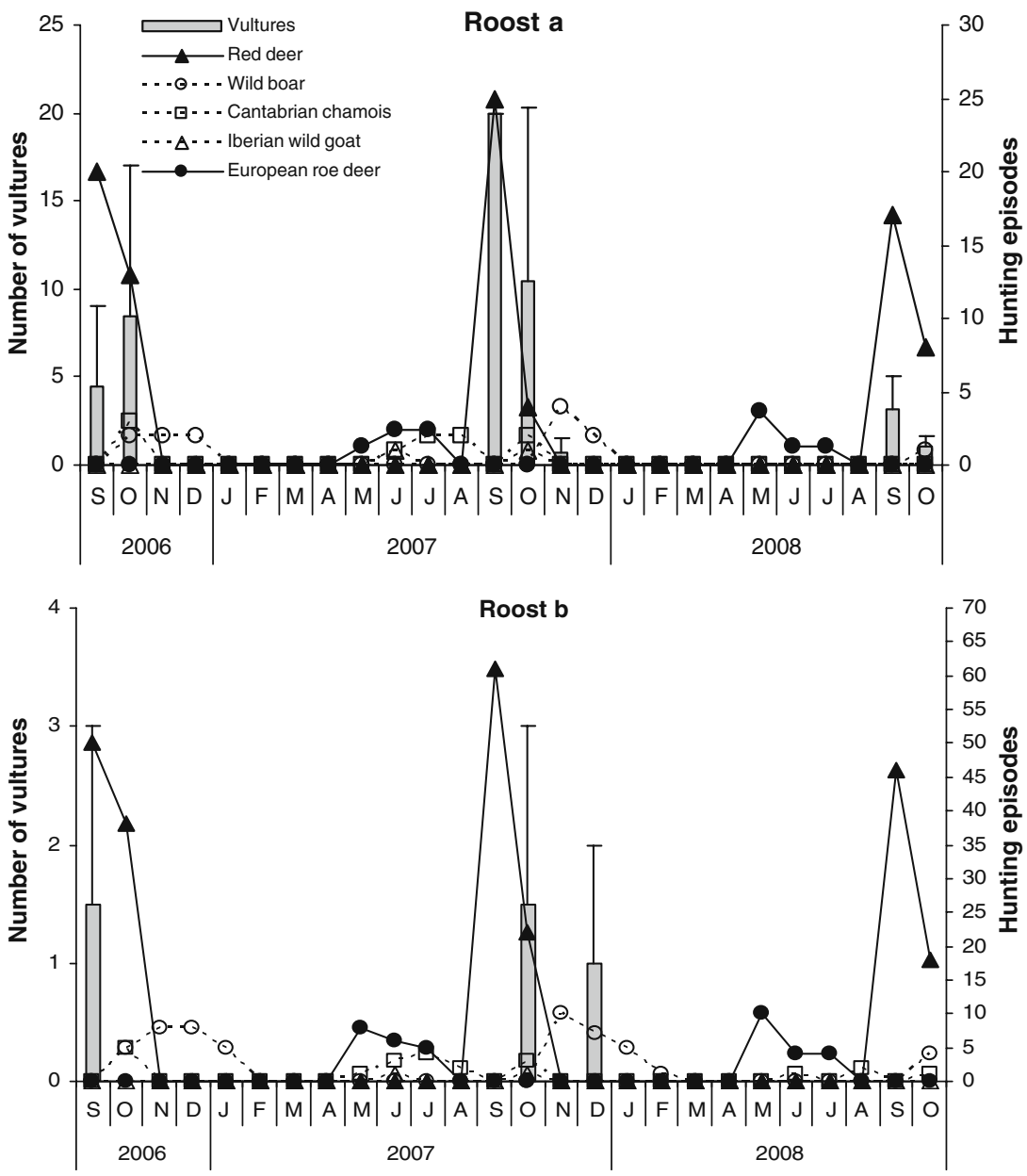
a, whereas this relationship was somewhat hidden in roost $\mathrm{b}$, as this roost was sometimes not used as much even when deer hunting occurred. In contrast, in one of the years, its use seemed to be related to wild boar hunting (Fig. 4). These differences between roosts were also showed by the best models performed (ESM 1), which included roost as the most important variable explaining number of vultures $\left(\omega_{\mathrm{i}}=0.85\right)$ and one of the most important explaining vulture presence $\left(\omega_{\mathrm{i}}=0.25\right.$; Fig. 5$)$. Red deer and wild boar seemed to be the game species most important as a food resource for vultures in the study area (Fig. 3). In fact, number of both shot red deer and shot wild boar within $3.5 \mathrm{~km}$ around the roosts were the best predictors of vulture presence at roosts, as shown by the lower AICc of the models, including them and the higher weight of these variables (Fig. 5 and ESM 1). Red deer was the species with the highest importance explaining number of vultures at roosts through both shots $\left(\omega_{\mathrm{i}}=0.26\right)$ and hunting season $\left(\omega_{\mathrm{i}}=\right.$ 0.18 ). Shot wild boars was also an important variable explaining vulture numbers $\left(\omega_{\mathrm{i}}=0.15\right)$. The presence of vultures at roosts was better explained by shot red deer and wild boar $\left(\omega_{\mathrm{i}}=0.26\right)$ and the hunting season of both species $\left(\omega_{\mathrm{i}}=0.22\right.$ and 0.19 , respectively; Fig. 5$)$.

Although the numbers of vultures in colonies fluctuated throughout the year, there were not significant differences between months (Kruskal-Wallis rank sum test: $\chi=9.854$, $P=0.45$ ). Nonetheless, small non-significant variations in the number of vultures at colonies could be observed coinciding with the period of use of roosts (SeptemberJanuary: mean \pm SE, $9 \pm 1$ vs February-August: $13 \pm 1$, Wilcoxon test: $W=37, P=0.10$; Fig. 6).

The hunting activity of red deer and wild boar in the whole study area could provide food to maintain around of
1,800 griffon vultures/half-year, i.e. more than the whole population of vultures in the study area (1,100 individuals).

\section{Discussion}

Vulture response to hunting activity

Griffon vultures positively responded in space and time to hunting, mainly of red deer but also of wild boar. Vultures were often seen consuming carcasses of these game species in the study area (Fig. 3) and used roosts located within sectors with high hunting activity of red deer and wild boar (Fig. 2). The temporal occupation of these roosts by vultures clearly fitted the hunting season of red deer (Fig. 4), with wild boar also influencing the presence of vultures at roosts (Fig. 5). The best statistical models showed that the presence and number of vultures at roosts was better related to number of hunting episodes of both red deer and wild boar (Fig. 5 and ESM 1).

The close relationship observed between occurrence and number of vultures at roosts and red deer hunting probably reflects the fact that red deer provides the highest amount of food, with around $90 \%$ (ca. $108 \mathrm{~kg}$ ) of each individual left on the field during trophy hunting season (Table 1) and with a considerable number of shots per year in the study area (ca. 700 shots/year; Fig. 3). Wild boar also explained the occurrence and number of vultures at roosts, probably because this species has the highest number of shots (ca. 1,900 individuals/year, Fig. 3), which provide a huge total quantity of potential food despite the small individual contribution (Table 1). Indeed, the better fit observed between vulture presence and wild boar shot at roost $b$ in
Fig. 5 The best ten explanatory variables included in the count (black bars) and zero-inflated (white bars) components of the final best models in order to explain vulture abundance and presence at roosts, respectively. Variable importance (weight) is represented by the sum of the Akaike weights $\left(\Sigma \omega_{\mathrm{m}}\right)$ of the best models (i.e. within $\Sigma \omega_{\mathrm{m}}=$ 0.95 ) containing that variable

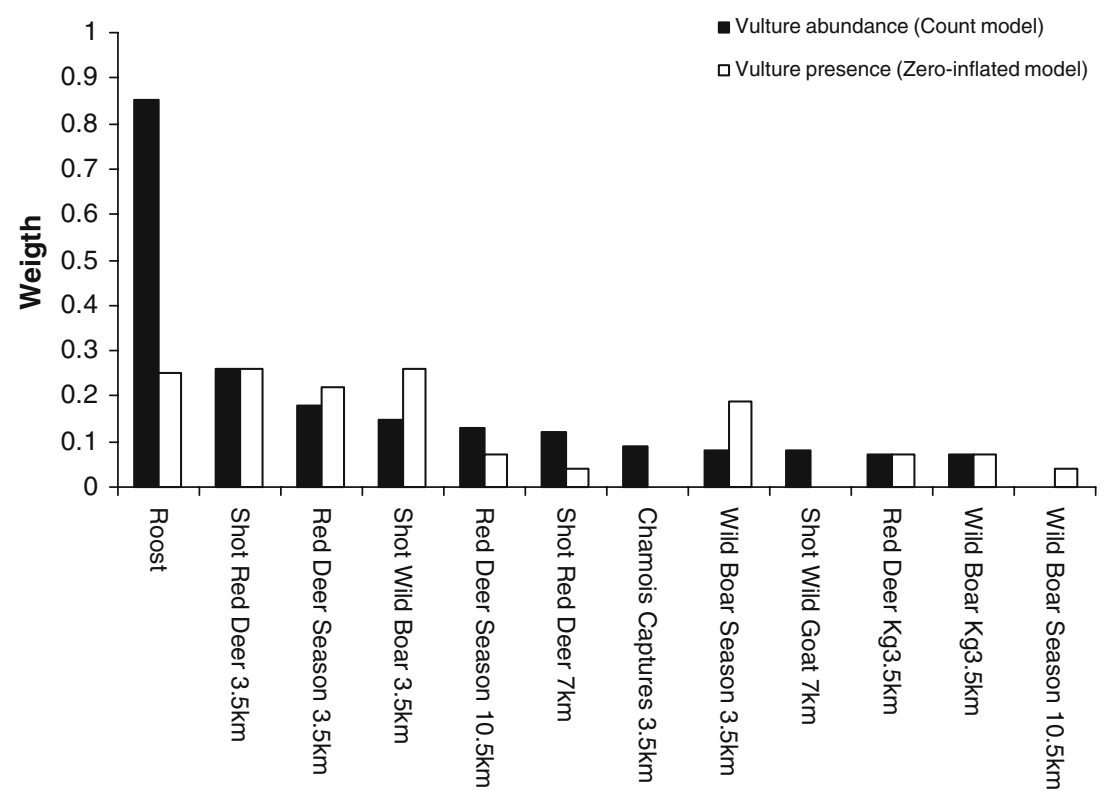


Fig. 6 Variation of the number of vultures (mean $\pm \mathrm{SE}$ ) at intensively surveyed colonies $(N=9)$ and roosts $(N=2)$ in the study area over a year

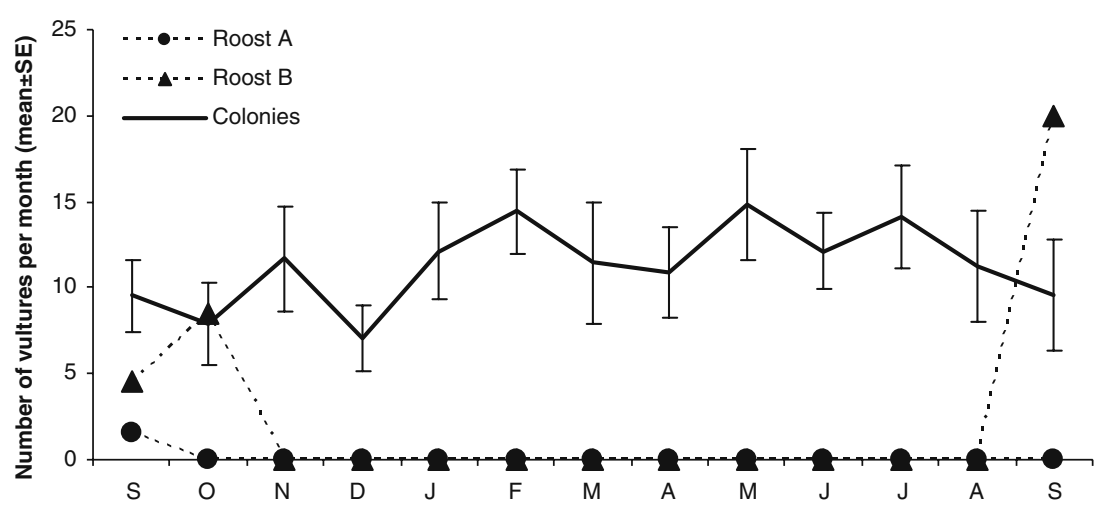

one of the study years could be due to the location of this roost in an area with many wild boar shoots (Fig. 2), which are mainly performed at late winter (Table 1 and Fig. 4), when there are less livestock on the field and less time for vultures to forage. The lower use of roosts by vultures during the last study year could be due to a slight decrease in the number of trophy red deer shot in 2008 around these roosts, together with a later beginning of the wild boar hunting season (Fig. 4; local authorities, personal communication).

In the areas with higher hunting activity of red deer and wild boar, there are no breeding colonies (Fig. 2), probably due to the fact that this area has very few limestone cliffs, and those cliffs are at high altitudes (Table 2). Additionally, game as food source is not available around the roosts at the time of incubation and rising of small chicks (i.e. March to May; Fig. 4), when distance from the colony may be a crucial factor (Xirouchakis and Mylonas 2004; Xirouchakis 2007) according to the optimal foraging theory (Schoener 1971). However, although this area apparently is not suitable for placing breeding colonies, vultures use it to forage, consuming food from hunting activity and using roost sites (Fig. 2), coinciding with the hunting season of red deer and wild boar (Figs. 4 and 6). It is known that vultures temporarily leave the breeding colony, using roost sites when an important resource in use is more than 9$10 \mathrm{~km}$ from the colonies (Xirouchakis and Mylonas 2004; Xirouchakis 2007). According to our models, roost use responded more strongly to hunting activity within a short distance (i.e. $3.5 \mathrm{~km}$ ) from the roost (Fig. 5 and ESM 1). This probably responds to the spatial distribution of roosts and colonies (Table 2 and Fig. 1). Vultures may probably access remains from any hunting activity occurring around the colonies from the colonies themselves, and only need to move to the roosts when they occur further than 9-10 km away from the colonies. Accordingly, the proximity between roosts and colonies (Table 2 and Fig. 1) could explain the low mean monthly number of vultures using the roosts (Fig. 4). Additionally, the time of the year (i.e. the beginning of the griffon vulture breeding period) could also limit the use of the roosts to non-breeding vultures. However, this proximity between breeding colonies and roosts could also favour a high turnover making the total number of vultures actually using the roosts considerably higher than that detected. Further research on this aspect is necessary through, for example, marking individuals or genotyping of shed feathers (Rudnick et al. 2008).

\section{Conservation implications}

The use of hunting remains might be of huge importance for vulture conservation within the current global situation of scavenging birds (Sekercioglu 2006; see "Introduction"). In Spain, the vulture populations are now rapidly responding to food shortages (Camiña and Montelío 2006), as shown by reductions in breeding parameters including the number of breeding pairs (Camiña 2007; Pérez 2007). In contrast, the griffon vulture population in our study area, non-feeding-station-dependent, has increased in over $30 \%$ of the number of breeding pairs in the last 4 years, with relatively high productivity rates (mean $\pm \mathrm{SE}, 0.74 \pm 0.04$ chicks/pair; $n=4$ years; authors unpublished data). This population status could be closely related to food availability through both extensive farming (Olea and Mateo-Tomás 2009) and hunting (this study), which provide abundant food throughout the year. Indeed, our study area supports a population of around 350 breeding pairs and around 1,100 individuals. Our estimates showed that around 1,807 vultures could be fed during 5-6 months only from available carcasses of hunted red deer and wild boar. In fact, we reported more sightings of vultures feeding on carcasses of wild ungulate $(69 \%)$ than that of livestock (31\%, Fig. 3). This indicates that, in this area, hunting activity could have a relevant role in maintaining the local griffon vulture population. This species starts reproduction during winter, so it is necessary to acquire and maintain good physical condition (Elosegui 1989). However, during winter, weather conditions are extremely hard, and food supplies from extensive livestock are very scarce (Olea and Mateo-Tomás 2009), so food from red deer and wild boar 
hunted during autumn-winter (Table 1) might have a relevant role in vulture reproduction and, therefore, in the conservation of the population.

However, possible negative aspects of hunting at both species and ecosystem levels must also be considered. In the case of the vultures, an exposure to lead from spent ammunition in large game carcasses has been shown and can potentially lead to lead toxicity (García-Fernández et al. 2005; Cade 2007; Dobrowolska and Melosik 2008). This lead poisoning may have important effects at both individual and population levels (Gangoso et al. 2009). In this context, due to the high consumption of hunting remains by vultures observed in our study area, it is necessary to monitor the effect of lead and other potential hazards on the scavenger population. At the ecosystem level, overabundance of game species could have negative impacts such as overgrazing or sanitary problems (Gortázar et al. 2006). In fact, in the study area, a possible negative impact of red deer overpopulation on capercaillie conservation has been highlighted (Pollo et al. 2003). Accordingly, a close control of hunting activity is necessary to minimise or eliminate those aspects that could have negative consequences on wildlife and ecosystem conservation.

Our study shows that hunting may also contribute to ecosystem conservation and provides a new useful piece of evidence to the science-based process required to progressively design sustainable hunting with a relevant role in ecosystem conservation (Thirgood and Redpath 2008).

Acknowledgements We thank hunters and local authorities of Asturias, Cantabria and Castilla y León who kindly responded our questions. The regional authorities of Asturias, Cantabria and Castilla y León provided information about hunting activity. O. Rodríguez and J. Marcos from Asturias government and J.A. Serdio from Cantabria government highly facilitated this task. J. Herrero, J. Tomás, E. Osorio, M. Gordaliza, J. Fernández, V. Mateo and L. Díez provided field assistance. S. Redpath and F.J. Purroy provided useful comments on the manuscript. P.M.T. was supported by a $\mathrm{PhD}$ scholarship funded by the Spanish Ministerio de Educación y Ciencia. P.P.O. was supported by research project CGL2006-05047/BOS from the Spanish Ministerio de Educación y Ciencia.

\section{References}

Baker JE (1997) Trophy hunting as a sustainable use of wildlife resources in southern and eastern Africa. J Sustain Tourism $5: 306-321$

Baldus RD, Damm GR, Wollscheid K (2008) Best practices in sustainable hunting - a guide to best practices from around the world, CIC-International Council for Game and Wildlife Conservation, Hungary. Downloadable from http://www.cicwildlife.org/index.php?id=412.

Benhaiem S, Delon M, Lourtet B, Cargnelutti B, Aulagnier S, Hewison AJM, Morellet N, Verheuden H (2008) Hunting increases vigilance levels in roe deer and modifies feeding site selection. Anim Behav 76:611-618
BirdLife International (2007) Gyps fulvus. In: IUCN 2007. 2007 IUCN red list of threatened species. www.iucnredlist.org. Downloaded on 20 October 2009.

Blanco-Aguiar JA, González-Jara P, Ferrero ME, Sánchez-Barbudo I, Virgós E, Villafuerte R, Dávila JA (2008) Assessment of game restocking contributions to anthropogenic hybridization: the case of the Iberian red-legged partridge. Anim Conserv 11:535-545

Brainerd S (2007) European charter on hunting and biodiversity. Document of the Standing Commitee 27th meeting, Strasbourg, 26-29 November 2007. Convention on the conservation of European wildlife and natural habitats. Downloadable from http://www.cic-wildlife.org/index.php?id=412.

Burnham KP, Anderson DR (2002) Model selection and multimodel inference: a practical information-theoretical approach. SpringerVerlag, New York

Cade TJ (2007) Exposure of California condors to lead from spent ammunition. J Wildl Manage 71:2125-2133

Camiña A (2007) Muladares para el buitre leonado en el sistema Ibérico: la recogida de cadáveres afecta al éxito reproductor de la especie. Quercus 261:22-27

Camiña A, Montelío E (2006) Griffon vulture Gyps fulvus food shortages in the Ebro Valley (NE Spain) caused by regulations against bovine spongiform encephalopathy (BSE). Acta Ornithol 41:7-13

Casas F, Mougeot F, Viñuela J, Bretagnolle V (2009) Effects of hunting on the behaviour and spatial distribution of farmland birds: importance of hunting-free refuges in agricultural areas. Anim Conserv 12:346-354

Del Moral JC, Martí R (2001) El Buitre Leonado en la Península Ibérica. III Censo. Nacional y I Censo Ibérico coordinado, 1999. Monografía no 7. SEO/BirdLife, Madrid

Dobrowolska A, Melosik M (2008) Bullet-derived lead in tissues of the wild boar (Sus scrofa) and red deer (Cervus elaphus). Eur. J Wildl Res 54:231-235

Donázar JA (1993) Los buitres ibéricos. Biología y conservación. Eds. Reyero, Madrid

Elosegui I (1989) Vautour fauve (Gyps fulvus), Gypaete barbu (Gypaetus barbatus), Percnoptère d'Egypte (Neophron percnopterus): Synthèse bibliographique et recherches. Acta Biologica Montana 3. Série Document de Travail

Gangoso L, Álvarez-Lloret P, Rodríguez-Navarro A, Mateo R, Hiraldo F, Donázar JA (2009) Long-term effects of lead poisoning on bone mineralization in vultures exposed to ammunition sources. Environ Pollut 157(2):569-574

García-Fernández AJ, Martínez-López E, Romero D, María-Mojica P, Godino A, Jiménez P (2005) High levels of blood lead in griffon vultures (Gyps fulvus) from Cazorla natural park (Southern Spain). Environ Toxicol 20:459-463

Gortázar C, Acevedo P, Ruiz-Fons F, Vicente J (2006) Disease risks and overabundance of game species. Eur J Wildl Res 52:81-87

Green RE, Taggart AM, Das D, Pain DJ, Kumar CS, Cunningham AA, Cuthbert R (2006) Collapse of Asian vulture populations: risk of mortality from residues of the veterinary drug diclofenac in carcasses of treated cattle. J Appl Ecol 43:949-956

Jackman S (2008) The pscl Package. Political Science Computacional Laboratory. Available at http://pscl.stanford.edu/

Junta de Castilla y León (2003) Libro del Parque Regional de Picos de Europa. Programa Parques Naturales de Castilla y León. Junta de Castilla y León, Valladolid

Junta de Castilla y León (2006) Memoria anual de la Reserva Regional de Caza de Riaño, 2005-2006.

Lemus JA, Blanco G, Grande J, Arroyo B, García-Montijano M (2008) Antibiotics threaten wildlife: circulating quinolone residues and disease in avian scavengers. PLoS ONE 3(1):e1444. doi:10.1371/journal.pone. 0001444 
Lindsey PA, Alexander R, Frank LG, Mathieson A, Romañach SS (2006) Potential of trophy hunting to create incentives for wildlife conservation in Africa where alternative wildlifebased land uses may not be viable. Anim Conserv 9:283291

Lindsey PA, Roulet PA, Romañach SS (2007) Economic and conservation significance of the trophy hunting industry in subSaharan Africa. Biol Conserv 134:455-469

Lozano J, Virgós E, Cabezas-Díaz S, Mangas JG (2007) Increase of large game species in Mediterranean areas: is the European wildcat (Felis silvestris) facing a new threat? Biol Conserv 138:321-329

Lucio A, Purroy FJ (1992) Caza y conservación de aves en España. Ardeola 39:85-98

Murn C, Anderson MD (2008) Activity patterns of African whitebacked vultures Gyps africanus in relation to different land-use practices and food availability. Ostrich 79(2):191-198

Nunez-Iturri G, Olsson O, Howe HF (2008) Hunting reduces recruitment of primate-dispersed trees in Amazonian Peru. Biol Conserv 141:1536-1546

Olea PP, Mateo-Tomás P (2009) The role of traditional farming practices in ecosystem conservation: the case of transhumance and vultures. Biol Conserv 142(8):1844-1853

Olea PP, García J, Falagán J (1999) Expansión del buitre leonado Gyps fulvus: tamaño de la población y parámetros reproductores en un área de reciente colonización. Ardeola 46:81-88

Pain DJ, Cunningham AA, Donald PF, Duckworth JW, Houston DC, Katzner T, Parry-Jones J, Poole C, Prakash V, Round P, Timmins R (2003) Causes and effects of temporospatial declines of Gyps vultures in Asia. Conserv Biol 17:661-671

Parker P (1987) Recruitment to food in black vultures: evidence for following from communal roosts. Anim Behav 35:1775-1785

Pérez JM (2007) Los buitres de Sierra Salvada sufren la recogida de ganado muerto. Quercus 261:30-32

Pollo CJ, Robles L, García-Miranda A, Otero R, Obeso JR (2003) Variaciones en la densidad y asociaciones espaciales entre ungulados silvestres y urogallo cantábrico. Ecología 17:199206

Principado de Asturias (2007) Plan de caza de las Reservas Regionales de Caza del Principado de Asturias 2007-2008. Informe inédito
R Development Core Team (2008) R: A language and environment for statistical computing. R Foundation for statistical computing, Vienna, Austria. http://www.R-project.org

Richards SA (2008) Dealing with overdispersed count data in applied ecology. J Appl Ecol 45:218-227

Rudnick JA, Katzner TE, Bragin EA, Dewoody JA (2008) A noninvasive genetic evaluation of population size, natal philopatry, and roosting behavior of non-breeding eastern Imperial Eagles (Aquila heliaca) in central Asia. Conserv Genet 9:667-676

Schoener TW (1971) Theory of feeding strategies. Annu Rev Ecol Syst 2:369-404

Sekercioglu CH (2006) Ecological significance of bird populations. In: del Hoyo J, Elliott A, Christie DA (eds) Handbook of the birds of the world, vol 11. Lynx Edicions, Barcelona, pp 15-51

Sekercioglu CH, Daily GC, Ehrlich PR (2004) Ecosystem consequences of bird declines. Proc Natl Acad Sci USA 101:18042-18047

Tella JL (2001) Action is needed now, or BSE crisis could wipe out endangered birds of prey. Nature 410:408

Thirgood S, Redpath S (2008) Hen harriers and red grouse: science, politics and human-wildlife conflict. J Appl Ecol 45:1550-1554

Thirgood S, Redpath S, Newton I, Hudson P (2000) Raptors and red grouse: conservation conflicts and management solutions. Conserv Biol 14:95-104

Valkama J, Korpimäki E, Arroyo B, Beja P, Bretagnolle V, Bro E, Kenward R, Mañosa S, Redpath S, Thirgood S, Viñuela J (2005) Birds of prey as limiting factors of gamebird populations in Europe: a review. Biol Rev 80:171-203

Viñuela J, Arroyo B (2002) Gamebird hunting and biodiversity conservation: synthesis, recommendations and future research priorities. Report to EC, Brussels. Downloadable from http:// digital.csic.es/handle/10261/8275

White PJC, Stoate C, Szczur J, Norris K (2008) Investigating the effects of predator removal and habitat management on nest success and breeding population size of a farmland passerine: a case study. Ibis 150(Suppl 1):178-190

Xirouchakis S (2007) Seasonal and activity pattern in Griffon Vulture (Gyps fulvus) colonies on the island of Crete (Greece). Ornis Fennica 84:39-46

Xirouchakis S, Mylonas M (2004) Griffon Vulture (Gyps fulvus) distribution and density in Crete. Isr J Zool 50:341-354 